\title{
Análise do efeito imediato da aplicação de técnicas vocais
}

\author{
Eliane Cristina Pereira ${ }^{1}$
}

Pereira EC. Análise do efeito imediato da aplicação de técnicas vocais [dissertação]. Curitiba (PR): Universidade Tuiuti do Paraná; 2009.

Técnicas vocais vêm sendo utilizadas na clínica fonoaudiológica com importantes resultados na reabilitação; porém poucos estudos visaram comprovar efetivamente seu uso e verificar quais efeitos são produzidos na voz e na laringe. $\mathrm{O}$ objetivo deste estudo é verificar o efeito imediato da aplicação de técnicas vocais: sons vibrantes, sons nasais e sobrearticulação, associadas. Participaram do estudo trinta e dois sujeitos do sexo feminino, com vozes normais a levemente alteradas, com média de idade de 28 anos. Foram realizadas análises perceptivo-auditiva, acústica, laringoestroboscópica e auto-perceptiva. Como resultados, verificou-se que houve diferença estatisticamente significativa pré e pós-aplicação de técnicas vocais na análise perceptivo-auditiva da vogal $/ \varepsilon /$ nos parâmetros grau geral da qualidade vocal $(\mathrm{p}=0,006)$, rouquidão $(\mathrm{p}=0,028)$ e estabilidade $(\mathrm{p}=0,003)$; na fala espontânea no parâmetro articulação ( $\mathrm{p}=0,020)$; na análise acústica nos parâmetros jitter em porcentagem $(\mathrm{p}=0,024)$, shimmer em porcentagem $(\mathrm{p}=0,021)$ e valor do harmônico superior $(p=0,000)$ e no exame de laringoestroboscopia no aumento do número de sujeitos que passou a ter fechamento glótico completo ( $\mathrm{p}=0,045)$, diminuição de sujeitos com fenda triangular médio posterior $(\mathrm{p}=0,006)$ e aumento do número de sujeitos com melhora da amplitude do movimento muco-ondulatória das pregas vocais $(\mathrm{p}=0,006)$. Dos relatos auto-perceptivos 30 sujeitos $(93,7 \%)$ declararam sensações positivas em relação à voz ou à laringe. Como conclusão percebeu-se que a realização das técnicas vocais melhorou significativamente parâmetros da análise perceptivo-auditiva, acústica e laringológica com sensações auto-perceptivas positivas. Estas técnicas podem ser utilizadas na obtenção de melhora vocal imediata, em mulheres com vozes normais a levemente alteradas.

Trabalho apresentado ao Programa de Pós-graduação em Distúrbios da Comunicação Humana da Universidade Tuiuti do Paraná - UTP - Curitiba (PR), Brasil, para obtenção do título de Mestre em Distúrbios da Comunicação Humana, sob a orientação do Prof. Dr. Jair Mendes Marques e co-orientação da Profa. Dra. Kelly Cristina Alves Silvério.

(1) Mestre, Fonoaudióloga da Prefeitura Municipal de Prudentópolis - Prudentópolis (PR), Brasil.

Endereço para correspondência: Eliane Cristina Pereira. R. Domingos Molinari, 127, Centro, Teixeira Soares (PR), Brasil. CEP: 84530-000. E-mail: elianecp@visaonet.com.br 